Попов E.A.

\title{
Преимущества и недостатки применения комплексной методологии в исследовании искусства
}

Аннотация: Основной целью предлагаемой статьи является обобщение методологических нюансов в исследовании феномена искусства. Данный ракурс работы позволил представить с точки зрения научного поиска деструктивные и созидательные моменты в определении методологических оснований исследования искусства и его форм. Главная проблема кроется в непродуманном повсеместном применении так называемого комплексного подхода или анализа, с которым не все исследователи справляются и потому такие работы обнаруживают некоторые методологические изъяны. В то же время показана роль междисциилинарного подхода в изучении феномена искусства, который имеет непреложную ценность для получения нового знания. Методология исследования определяется системностью в анализе бытования искусства и его форм в жизни человека и общества. Основные выводы исследования определяются следующими положениями: 1) при изучении феномена искусства имеет значение продуманное и обоснованное использование комплексного подхода или анализа; понимание данного ракурса изучения феномена искусства как простой совокупности методов или приемов исследования существенно опрощает работу; 2) междисциплинарный подход имеет явные преимущества при исследовании искусства, однако требует соблюдения важных правил, игнорирование которых способно привести к рискам получения декларативных и неубедительных с научной точки зрения результатов.

Ключевые слова: Культура, Общество, философия, Ценности, интеграция наук, познание, искусство, методология, наука, междисциплинарность.

Review: The main purpose of the present research article is to summarize methodological peculiarities of art research. The author's approach to the topic has allowed to describe destructive and constructive aspects of defining methodological grounds for studying art and artistic forms from the scientific point of view. According to the author, the main problem is the unreasoned application of the so-called integrated approach and analysis. Not all researchers can handle this approach so their researches have methodological gaps. On the other hand, the author emphasizes the crucial role of the interdisciplinary approach in studying the phenomenon of art. The methodological basis of the research is defined by the systems analysis of arts in the human life and society. The main conclusions of the research are the following: 1) Reasoned and adequate application of the integrated approach and analysis is very important for studying the phenomenon of art. The idea of art studies as a plain combination of research methods and/or techniques makes it much easier to achieve the research objectives. 2) Interdisciplinary approach has certain advantages, however, important rules are to be observed in order to avoid the risk of obtaining declarative or invalid results.

Keywords: Interdisciplinarity, science, methodology, art, cognition, integration of sciences, values, philosophy, society, culture.

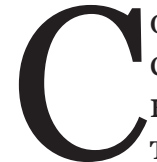

овременные подходы в исследовании социокультурных явлений и феноменов довольно разнообразны и продиктованы множеством обстоятельств, среди которых и ориентация наук и знаний на антропологический поворот, и изменение масштаба отношений человека и культуры, и необходимость рассматривать мир и его элементы на междисциплинарном уровне и т.д. Одним словом от науки требуется не просто акцентированная позиция относительно тех или иных актуальных проблем, но и уста- новление эвристичных связей друг с другом, что позволит получать более значительные результаты исследований и применять их на практике.

Междисциплинарные отношения наук и знаний строятся на основе следующих важнейших принципов: 1) общность объектнопредметного пространства; 2) схожесть или взаимодополняемость категориальных систем; 3) комплексная направленность методологических оснований без избыточности; 4) проблематизация в рассмотрении явлений, 
феноменов и процессов; 5) выбор адекватного методического обеспечения; 6) возможность использования результатов исследования в других научных областях или для изучения других объектов окружающей реальности; 7) следование законам научности, остающимся приоритетными для изучения мира и человека в нем. Как видим, для осуществления междисциплинарного синтеза или точнее взаимодействия наук и знаний необходимо учитывать важные обстоятельства, игнорирование которых не позволит полноценно использовать в исследовании любых явлений и процессов данный подход. Поэтому зачастую исследователи не учитывают тот факт, что междисциплинарный подход будет являться таковым только тогда, когда он в полной мере обеспечивает широту и полноту исследования; в противном случае его нельзя будет назвать междисциплинарным. Упрощение этой направленности исследования способно не просто привести ученого в тупик, но и сделать полученные им выводы декларативными, описательными и в конечном счете неубедительными с научной точки зрения.

В изучении искусства важна каждая мелочь, в том числе и возможность использования междисциплинарного подхода. Очевидно, что в рамках какого-то одного направления или одной научной области изучение искусства не будет плодотворным не только по той причине, что феномен искусства сложен и многообразен в трактовках и интерпретациях, но и в связи с тем, что искусство встроено в систему отношений человека, культуры, общества, государства. А значит, для полноты исследования необходимо привлекать ресурсы разных наук и знаний, иногда наряду с социогуманитарными и естественнонаучные дисциплины. Вместе с тем такой ракурс изучения искусства не может не учитывать и узкой специализации различных наук и знаний, поэтому приоритет сохраняется за теми дисциплинами, которые прежде всего сконцентрированы на всестороннем рассмотрении искусства. Здесь имеются в виду искусствоведение, философия искусства, социология искусства и отчасти культурология. За ними вне всякого сомнения сохраняется выраженная тенденция системного изучения феномена искусства. Причем существенный накопленный опыт исследования позволяет указанным отраслям науки более предметно и прицельно изучать искусство во всем многообразии его форм, во взаимодействии с иными видами духовной жизни человека и общества. Почему однако все чаще возникает вопрос о необходимости именно междисциплинарного исследования искусства и проблемы его включенности в систему различных отношений - социальных, экономических, политических и других? Ответ на этот вопрос связан с выяснением преимуществ междисциплинарного ракурса изучения искусства. При этом важным моментом, на наш взгляд, является отказ от абсолютизации данного исследовательского направления, поскольку в противном случае возникает вопрос и о сохранении уникальности тех наук и знаний, многие из которых в течение довольно длительного времени занимались всесторонним анализом проблем становления и развития искусства.

В исследованиях последних лет все чаще можно встретить в качестве базовой методологии исследования разных явлений и процессов окружающей реальности комплексныци анализ. Как полагают исследователи, видимо, в их руках оказался довольно прогрессивный способ оценки развития тех или иных состояний мира, человека, культуры, наконец, искусства. Само название комплексного анализа, по сути, должно предвосхитить желание любого ученого объять необъятное и получить новые результаты, примечательные в масштабе любой науки или какой-либо ее отрасли. Главным преимуществом такого вектора исследований может быть назван сосредоточенный взгляд на предмет изучения, при этом особое значение приобретает характер привлекаемых ресурсов различных наук и знаний для поддержания такого вдумчивого и ответственного отношения к рассматриваемому атрибуту бытия. Вместе с тем «комплексность» как способ освоения новых или уже известных реалий окружающего мира обладает такой выраженной особенностью, которая не позволяет рассчитывать на серьезный прорыв в изучении того или иного объекта. Действительно, комплексный анализ богат на свои возможности, но он также обладает по меньшей мере тремя очевидными недостатками и потому, например, в исследовании искусства, а равно как и других подобных феноменов, не является показательным и надежным.

Во-первых, комплексный анализ довольно хаотичен по сути, не имеет четко определенной стратегии и тактики исследования, на самом деле «схватывает» лишь те стороны изучаемого объекта, которые имеют значение для ученого и требуют с его стороны 
рефлексии; таким образом, комплексный анализ не изменяет масштаб самого феномена, но между тем способен внести сумятицу в системную методологию и в конечном итоге привести к «переоценке» объекта изучения. Например, искусствовед ставит своей задачей изучить сибирское ковроткачество и определяет комплексную методологию основой исследования. Почему его не устраивает при этом традиционный социокультурный и, допустим, стилистический анализ, позволяющий выявить примечательные особенности стиля, цвета, модификации ковров и т.д.? Именно этот ракурс исследования позволит получить представление о культурно-историческом контексте, оказавшем влияние на становление и развитие ковроткачества в Сибири. Комплексный анализ (или комплексная методология) выбирается для иллюстрации тех же особенностей - влияния культурного ландшафта, мастерства ремесленника, условий для производства ковра и т.д., но набором средств, не всегда подходящих для этого: сравнительный, интерпретативный, герменевтический, антропологический и другие подходы.

Во-вторых, комплексный анализ для рационализации исследования в основном представляет собой технологический процесс, целью которого является отыскание эффективного и действенного инструмента для познания мира. Очевидно, что такой инструмент может быть получен в результате адаптации методов прикладного исследования; таким образом, выбор определенных методов подчинен скорее не функциональной цели - увидеть взаимосвязь и влияние явлений и феноменов друг на друга, а рациональной - продемонстрировать возможности технологии и тем самым обосновать выгоду именно такого пути исследования. Здесь можно, к примеру, рассмотреть случай с использованием интерпретативного подхода, который позволяет исследователю при изучении, скажем, памятников деревянного зодчества увидеть всю гамму символики, согласующейся с выраженным контекстом эпохи. Но искусствовед привлекает комплексный анализ, добавляя к интерпретативному подходу избыточные герменевтический, семантический (семиотический) и т.д.

B-третьих, комплексный анализ, как правило, сопровождается нагромождением или избыточностью «комплекса» методологических подходов. Поэтому нередко системный подход дополняется практически всеми дру- гими известными направлениями исследования: аксиологическим, антропологическим, антропосоциетальным, этнографическим, герменевтическим и т.д. Иногда исследователь даже не отдает себе отчет в том, что такое сопряжение различных самодостаточных методологических подходов способно, по сути, разорвать предмет исследования на мелкие элементы и элементики, что не добавляет научного веса всей проделанной работе. Однако это обстоятельство вовсе не останавливает исследователей, а напротив, воспринимается ими как само собой разумеющийся факт и толкает их к новым, лишенным нередко эвристической ценности обобщениям и выводам. Конечно, если исходить из тезиса П. Бурдье: «...произведение искусства всегда содержит что-то невыразимое...» (курсив автора цитаты. - E. П.) [1, с. 66], то можно предвидеть и аргументы исследователей в пользу привлечения комплексного анализа, способного будто бы раскрыть эту невыразимость или, по крайней мере, рассчитывать на это в ближайшей перспективе. Однако стоит констатировать: если речь идет об искусстве, то комплексный анализ обнаруживает свои недостатки более отчетливо: 1) операционализация искусства, не подкрепленная ценностносмысловыми обобщениями, что в конечном счете приводит к утилитаризации искусства и его выраженному оповседневниванию; 2) отсутствие меры вещей, когда исследователь искусства, не желая проникать в глубины и тайны бытия и отказываясь долго и скрупулезно отыскивать «невыразимое», использует совокупность разных подходов для отвлечения внимания от самого искусства, но при этом иногда не осознает, что подменяет феномен искусства набором его функций и возможных дисфункциональных проявлений; 3) «парадигмальный конфликт», который со всей очевидностью обозначается в русле комплексного анализа искусства, а по мысли Н. С. Розова, вызванный наличием «существенных противоречий между общими суждениями о явлениях прошлого в двух или более исторических описаниях» [2, с. 159]. Вообще говоря, такой конфликт - не редкость в науке на всем протяжении ее становления и развития, но его острота усугубляется тогда, когда речь заходит не только о встрече времен и эпох, традиций и инноваций, но и о таких ускользающих для познания феноменов, каким и является искусство. Важно понять, насколько существенны и непреодоли- 
мы возможные границы между искусством и человеком, искусством и государством, наконец, искусством и обществом. Но комплексный подход в том виде, как он используется в современной науке, вряд ли способен дать ответы на эти актуальные вопросы. Более того - он точно способен внести сумятицу в исследовательский опыт и, возможно, вычленит и абсолютизирует такие стороны бытования феномена или явления, которые вовсе не будут подтверждены другими исследованиями. Такая абсолютизация по отношению к искусству никак не оправдана и граничит с заблуждением.

В социогуманитарных дисциплинах можно встретить и перенесение «комплексного характера» с методологии на методику исследования - оказывается, применение тех или иных методик и приемов в известной совокупности теоретических и эмпирических, общенаучных и частных способов осмысления действительности также имеет комплексный характер. На самом деле здесь обнаруживается проблема несколько иного свойства: неразличение методологии и методики исследования. Так, в некоторых диссертациях по искусствоведению упоминание о методологии попросту отсутствует, зато методы исследования перечисляются в комплексном единстве; Ю.А. Казанцева, к примеру, в автореферате своей работы отмечает: «Методы исследования - разнообразны, носят комплексный характер, сочетающий теоретико-аналитический, исторический, исполнительский, источниковедческий и статистический подходы, методы слухового анализа и компьютерной обработки звука» [3, с. 9]. В этом перечне усматривается полет мысли исследователя много дальше собственно предмета изучения, а кроме того, здесь явно затруднительно выявить стратегическую линию исследования. К чему это может привести? По-видимому, к тому, что жанр научного труда может смениться на обмен впечатлениями или диспут с заинтересованными коллегами. Сам автор работы, кстати, это обстоятельство и подтверждает: «Помимо музыкально-теоретического анализа, мы стремились раскрыть художественные образы пьес. Мы понимаем всю субъективность музыкальных впечатлений. И всё же мы попытались говорить о тех образах, ассоциациях и настроениях, которые та или иная пьеса вызывает у нас...» [3, с. 12]. Субъективность, впечатлительность, попытки порассуждать, ассоциации и настроения - это, очевидно, те состояния, которые сопутствуют зрителю, читателю и слушателю, но от исследователя феномена искусства мы склонны ожидать все же иных позиций, выдержанных и определенных, даже если речь идет относительно искусства. Но в данном случае растерянность исследователя объясняется в том числе и отсутствием четкой проработки методологических оснований исследования.

Что касается междисциплинарного подхода, то его главная особенность и, повидимому, достоинство определяется тем обстоятельством, что он прицельно, с использованием тех или иных преимуществ разных научных дисциплин и знаний приближается к объекту изучения. Прицельность иногда становится едва ли не определяющим фактором и залогом успешности всей научной работы. Междисциплинарный подход по своей сути не подменяет профильную дисциплину, например, искусствоведение, направленное на изучение искусства и разнообразных форм его бытования, но вместе с тем существенно дополняет ракурс изучения и к тому же помогает конкретной науке преодолеть возможную исследовательскую инерцию, возникшую в результате длительного анализа специфического объекта. Поэтому междисциплинарный подход сегодня - это совокупность усилий множества научных дисциплин и знаний, подчиненных цели отыскания истины об одном и том же предмете исследования. Важно здесь подчеркнуть: об одном и том же предмете; комплексный анализ направлен на установление связей явлений и феноменов друг с другом, выяснение их форм и способов развития, междисциплинарный подход усиливает, укрупняет, возводит в ранг важнейшей системы некий предмет, который раскрывается в многообразии форм и тенденций динамики. Такой ракурс оценки предмета исследования предложила, к примеру, Л. И. Нехвядович в своей статье «Многообразие подходов к определению понятия «этническая традиция»» [4, с. 179-184]. По смыслу названия данной работы автор, как мы полагаем, применил как раз комплексный подход («многообразие подходов»), однако в самой статье отчетливо проявляет себя именно междисциплинарный подход, поскольку ученый сосредоточил внимание на одном предмете исследования и раскрыл его содержание с привлечением материалов различных наук - этнологии, истории, культурологии, искусствоведения и т.д. Таким образом, для определения вектора междисци- 
плинарности необходимо прямо называть те области наук и знаний, которые исследователи привлекают для прицельного изучения. С другой стороны, междисциплинарный ракурс решения сложной научной задачи позволяет увидеть конструктивный характер в переосмыслении бытования тех или иных традиционных или инновационных феноменов и явлений в пространстве культуры или же в среде искусства. Такую направленность подтвердила, в частности, Т. А. Семилет в одной и своих статей [5, с. 203-206].

Исходя из тех принципов междисциплинарного подхода, о которых речь шла в начале нашей статьи, мы можем продемонстрировать возможности его применения для исследования феномена искусства. Но прежде необходимо сделать некоторые замечания, позволяющие в какой-то степени нивелировать возможные противоречия, которые, вне всякого сомнения, возникнут при рассмотрении такого сложного образования как искусство.

Пожалуй, главный акцент в содружестве наук, поставивших своей целью исследование искусства и форм его бытования, должно стать преодоление очень мощного и фундаментального давления - философско-мировоззренческого. Искусство - это, конечно, вотчина и основа всестороннего изучения в философии. По своему деликатному и сакральному характеру искусство как объект исследования более всего подходит именно для философии, проникающей в глубины подобных таинственных феноменов. Но все дело в том, что такая сугубо философская центрация внимания на искусстве отдаляет этот феномен от наук и знаний, смущает их и наталкивает на мысль о неподъемности ноши: искусство - это неуловимая субстанция, с какой стороны к ее исследованию не приближайся. Действительно, это обстоятельство может поставить науки в тупик и увести их далеко от изучения искусства. Этот момент заслуживает внимания и рефлексии: каким образом науки в своем междисциплинарном взаимодействии могут этот философско-мировоззренческий крен преодолеть. Если же не обращать на это внимания, то скорее всего апелляции к довольно пространному материалу из философии искусства все время будут отодвигать исследователя от поставленной цели или точнее уводить его в проблематику философского характера. По этой причине он может не достичь результата, на который рассчитывал в самом начале научного труда. Показательным, на наш взгляд, является пример с социологией искусства. Эта отрасль социологической науки давно зарекомендовала себя как авторитетная дисциплина в изучении взаимодействия искусства и общества, однако в последнее время искусство стало малопривлекательной предметной областью для социологов, требующей известной терпеливости в обращении с тонкими материями, предельной внимательности в выборе методов и обобщении результатов исследования. Таким образом, «большая» социология стремительно идет вперед, а вот социология искусства сходит на нет, становится своего рода довеском, например, к социологии культуры или даже социологии духовной жизни.

С другой стороны, если следовать определенной логике вещей, то невозможно в исследованиях искусства провести четкой границы в осмыслении феноменов культуры и искусства. Очевидно, что для одних дисциплин и одних исследователей данный вопрос не будет столь уж актуальным, а для других станет принципиальным и потребует в таком случае дополнительных усилий. Однако и в первом случае, и во втором проблема остается, и она может серьезным образом повлиять на методологический ракурс исследования. По словам Н.А. Касавиной, «культура...способствует направлению, обогащению, развитию человека и его индивидуальных переживаний» [6, с. 48] или «границы между индивидом и культурой могут быть противоречивы и болезненны» [6, с. 54]. Так или иначе исследователь вынужден обращаться к пограничным состояниям человека, общества, культуры, в этом сосредоточено зачастую зерно всех мировоззренческих и межпоколенных проблем. Но точно так же, когда речь заходит о феномене искусства, проигнорировать соотношение масштабов и значений культуры и искусства не удастся. Кстати, подчас исследователь, рассуждая об искусстве, сам того не замечая, переходит на другой объект, и таким объектом становится культура. Например, использование культурно-исторической методологии в искусствоведении требует от ученого четкости и последовательности в анализе эпох и форм искусства, им соответствующих по различным основаниям. И здесь важно как раз «правильно» соотнести рассматриваемые явления: культура - это мировоззренческий контекст эпохи, искусство - это результат оценивания эпохи, форма отношения к действительности, рефлексия относительно времени, пространства, человека, общества, природы. 
В этом смысле, по меткому выражению Дж. Гессерта, «...искусство способно использовать коллективные энергии - эпические, мегаманиакальные, претендующие на пересоздание мира, и - разрушительные - которые индустриальная цивилизация представляет в распоряжение науки, правительства, военных и бизнеса» [7, с. 146].

Если же исследователь, к примеру, ставит своей задачей изучить конкретную форму искусства, творческое наследие художника или, допустим, региональную специфику развития искусства, то он ближе всего духу и принципам искусствоведения, однако и здесь обойти стороной социокультурную динамику вряд ли возможно, поэтому «скачки» от искусства к культуре и наоборот - не редкость в таких исследованиях. Ярким примером, на наш взгляд, служит анализ идейно-художественного своеобразия творчества того или иного автора, художника, архитектора и т.д. Условно говоря, когда речь заходит о художественном своеобразии, то исследователю, разумеется, приходится оперировать соответствующими категориями и понятиями, он обращается к арсеналу аналитических средств искусствоведческой науки. Когда же дело доходит до выявления идейной специфики творчества, то в данном случае избежать выяснения социокультурного контекста эпохи не представляется возможным, а поэтому исследователь вынужден делать и философские, и культурологические, и нередко психологические обобщения. Можно сказать, таким образом, что подобное положение вещей - это венец работ, не ставящих своей задачей разделение искусства и культуры, но, напротив, доказывающих необходимость рассмотрения их развития в единстве. Для иллюстрации данного обстоятельства обратимся к корпусу диссертационных работ по искусствоведению. Так, например, Е.Е. Никулина в работе, посвященной анализу стилевых особенностей иконописи Карелии, формулирует гипотезу исследования следующим образом: «Своеобразие иконописи Карелии второй половины XVII - середины XVIII вв. во многом определяется теми влияниями, которые в течение долгого времени проникали в культовое искусство Карелии, - это приемы, идущие из народного искусства и стиля барокко, питательной почвой для появления которых с одной стороны послужила обновленная политическая ситуация, с другой - христианско-языческий синкретизм» $[8$, с. 5$]$. Автор апеллирует и к политической ситуации, обусловившей своеобразие рассматриваемого феномена искусства, и к религиозно-мировоззренческому синкретизму, являющемуся чаще всего объектом социокультурного анализа. Конечно, оставаться в рамках только искусствоведения, когда речь идет о столь сложных формах бытования искусства, практически невозможно, поэтому едва ли не единственным надежным способом научного осмысления или переосмысления феноменов искусства продолжает оставаться междисциплинарный подход.

Специфика междисциплинарного подхода, как уже отмечалось, заключается в привлечении научно-исследовательских ресурсов различных наук и знаний для получения новых эвристически ценных данных об изучаемом объекте. При этом, разумеется, необходимо руководствоваться определенными требованиями, следование которым в значительной степени повышает научную значимость полученных результатов и их верифицируемость. Некоторые исследователи склонны полагать, что «социально-гуманитарные науки пересекаются и всегда могут взаимоинтерпретироваться, их развитие происходит во многом путем перекрестных заимствований. Парадокс заключается в том, что даже стремление к синтезу приводит к бесконечной фрагментации» [9, с. 16]. Действительно, фрагментация знаний, их мозаичность - частые спутники современной науки, вместе с тем междисциплинарный подход не только ставит своей задачей объединение различных дисциплин для поиска нового, но и в том числе преодоление фрагментации знаний. Достигается это в тех случаях, если данный методологический подход применяется не для красного словца как модная экипировка науки, а как действенный и эффективный способ получения ценного знания.

Как уже отмечалось выше, для адекватного использования междисциплинарного подхода при изучении феномена искусства и его форм значение имеет общность объектно-предметного пространства. Риск непродуктивного применения междисциплинарного подхода в исследовании искусства значительно повышается, если у дисциплин отсутствует общность объектно-предметного пространства. В искусствоведении, например, существует научная специальность 17.00.06 - техническая эстетика и дизайн, которая уже по своей формулировке обладает выраженной спецификой междисциплинарности; очевидно, что для обеспечения именно искусствоведческого анализа в рамках 
данного направления исследований необходимо привлекать потенциал разных научных дисциплин, но в то же время оставаться в границах своей профилирующей научной специальности и следовать логике научного труда. Но вопрос не только в том, как правильно выбрать ракурс исследования и адекватным образом построить его стратегию, но и в соответствии технической эстетики и дизайна канонам искусства. По выражению В.В. Бычкова, «...никто из профессионалов не сомневался в том, что именно эстетические качества искусства, которые чаще всего сводились к прекрасному и возвышенному, относятся к его сущности, и если произведение искусства не содержит их, независимо от того, что оно изображает или выражает, оно и не считалось подлинным произведением искусства. Именно на основе соответствия этому признаку, который называется художественностью, и выстроена практически вся история искусства от древнейших времен до середины XX в., по крайней мере, именно он лежал в основе формирования коллекций всех крупнейших художественных музеев мира и многих частных коллекционеров, и с опорой на него формировались основные науки об искусстве - искусствознание, теория искусства и во многом эстетика, понимавшаяся нередко как философия искусства (Шеллинг, Гегель)» (курсив автора цитаты. - E. П.) [10, с. 3]. Как видим, ключевым критерием искусства попрежнему признается классический признак художественности, но именно междисциплинарный аспект рассмотрения феномена искусства в многообразии его форм и проявлений позволяет сместить акцент на другие не менее важные признаки искусства - психологизм, историзм, технологизм и даже функциональность. Но другие дисциплины - не теория искусства, не эстетика - не обращаются к изучению искусства столь последовательно и методично: не ставят такой задачи и в принципе не рассматривают искусство как важнейший элемент человеческого бытия и т.д. Значит ли это, что такие дисциплины не могут в сотрудничестве с другими научными областями проявить интерес к феномену искусства и изменить свое отношение к нему. Разумеется, нет. В русле междисциплинарного анализа общность объектно-предметного пространства достигается не простой констатацией того, что конкретная научная дисциплина непосредственно изучает искусство, а установлением системных отношений между различными феноменами и явлениями бытия.
В то же время междисциплинарный анализ предполагает комплексную направленность методологических оснований, но особо следует подчеркнуть: без избыточности. Комплексность в изучении явлений мира вовсе не обозначает, что нужно брать весь доступный арсенал научно-исследовательских технологий и применять его в отношении к тому или иному объекту. Чаще всего такая чрезмерная комплексность обнаруживается в использовании методов исследования, и автор в этой иногда не в силах остановиться перед магией комплексной методики. В одной из упоминавшихся выше диссертаций можно, например, увидеть совокупность почти всех основных методов искусствоведческого анализа, которые взяты на вооружение данной областью науки, но также, как полагает диссертант, необходимы и для исследования его предмета: источниковедческий, историкоописательный, стилистический, сравнительноаналитический, типологический, иконографический, иконологический, интерпретативный [8, с. 6]. Как водится, довольно наукоемкие и самодостаточные методы стилистического и интерпретативного анализа кажутся исследователю недостаточными, поэтому для придания научной значимости проделанной работе он все чаще избирает путь комплексного анализа, но при этом выбор совокупности методов «с избытком» как раз не добавляет веса такой работе, а заставляет задуматься о стратегии исследования и увидеть в ней серьезные изъяны. Главной проблемой становится размытость концепции и ускользание предмета исследования в области отдаленные, не дающие четкого представления о характере включенности этого объекта в отношения с другими феноменами и явлениями. Следовательно, начинает доминировать форма, а не содержание. Для изучения искусства такой перевертыш угрожает появлением синдрома недосказанности, недовоплощения и в целом неаналитичности. По мнению Г. Зиммеля, «... так, мы приближаем к себе единые образования искусства, формирования жизни, речи лишь настолько, чтобы сопоставить интерес к их чистой форме с интересом к их чистому содержанию...» [11, с. 36]. В искусстве, разумеется, трудно отыскать чистую форму и чистое содержание, однако комплексность в исследовании бытия искусства порождает возврат к форме, а содержание при этом становится неуловимым или вторичным элементом в процессе изучения. Задача комплексной методологии - повернуть этот исследовательский ракурс в противоположную сторону и очертить границы феноме- 
на или явления в системе взаимодействующих друг с другом феноменов, например, искусство - это мир эмоционально-чувственный, а политика - рационально-прагматический, искусство - бытийная ценность, а политика - социальная ценность, наконец, искусство - это способ консолидации общества, а политика - способ упорядочения общественных отношений и т.д.
Междисциплинарный подход в изучении искусства - это неизбежная данность, и очевидно, что в условиях полифонизма мира, изменений границ художественности, эстетичности, трансформации критериев произведения искусства именно это исследовательское направление позволяет рассчитывать на получение важных результатов.

\section{Библиография:}

1. Бурдье П. Практический смысл / Пер. с фр. СПб.: Алетейя, 2001. С. 24.

2. Розов Н.С. Новая актуальность философии истории и проблема согласования описаний прошлого // Общественные науки и современность. 2014. № 2. С. 150-160.

3. Казанцева Ю.А. Фортепианные пьесы Арнольда Шёнберга: эволюция стиля и проблемы интерпретации: Автореф. дисс. ... на соиск. канд. искусствоведения // http://vak.ed.gov.ru/dis-details?xPARAM=182355

4. Нехвядович Л.И. Многообразие подходов к определению понятия «этническая традиция»// Известия Алтайского государственного университета. 2010. № 4-3. С. 179-184.

5. Семилет Т.А. Конструктивные стратегии выхода из тупика современной социокультурной ситуации: о книге А.В. Иванова, И.В. Фотиевой, М.Ю. Шишина «На путях к новой цивилизации (Очерки духовно-экологического мировоззрения)» // Известия Алтайского государственного университета. 2015. T. 1. № 3(87). С. 203-206.

6. Касавина Н.А. Экзистенциальный опыт как феномен культуры // Вопросы философии. 2014. № 10. С. 46-56.

7. Гессерт Дж. История искусства с привлечением ДНК // Логос. 2006. № 4. С. 127-147.

8. Никулина Е.Е. Стилевые особенности иконописи Карелии середины XVII -второй половины XVIII веков. По материалам коллекции музея изобразительных искусств Республики Карелия: Автореф. дисс. ... на соиск. канд. искусствоведения // http://vak.ed.gov.ru/dis-details?xPARAM=180449

9. Смирнов И.П. История мысли - история философии: проблема дифференциации // Философские науки. 2013. № 4. С. 31-34.

10. Бычков В.В. Художественность как сущностный принцип искусства // Вопросы философии. 2015. № 3. С. 3-14.

11. Зиммель Г. Избранное: в 2-х т. Т. 1. Философия культуры. М.: Юрист, 1996. С. 51.

\section{References (transliterated):}

1. $\quad$ Burd'e P. Prakticheskii smysl / Per. s fr. SPb.: Aleteiya, 2001. S. 24.

2. Rozov N.S. Novaya aktual'nost' filosofii istorii i problema soglasovaniya opisanii proshlogo // Obshchestvennye nauki i sovremennost'. 2014. № 2. S. 150-160.

3. Kazantseva Yu.A. Fortepiannye p'esy Arnol'da Shenberga: evolyutsiya stilya i problemy interpretatsii: Avtoref. diss. ... na soisk. kand. iskusstvovedeniya // http://vak.ed.gov.ru/dis-details?xPARAM=182355

4. Nekhvyadovich L.I. Mnogoobrazie podkhodov k opredeleniyu ponyatiya «etnicheskaya traditsiya» // Izvestiya Altaiskogo gosudarstvennogo universiteta. 2010. № 4-3. S. 179-184.

5. Semilet T.A. Konstruktivnye strategii vykhoda iz tupika sovremennoi sotsiokul'turnoi situatsii: o knige A.V. Ivanova, I.V. Fotievoi, M.Yu. Shishina «Na putyakh k novoi tsivilizatsii (Ocherki dukhovno-ekologicheskogo mirovozzreniya)»// Izvestiya Altaiskogo gosudarstvennogo universiteta. 2015. T. 1. № 3(87). S. $203-206$.

6. Kasavina N.A. Ekzistentsial'nyi opyt kak fenomen kul’tury // Voprosy filosofii. 2014. № 10. S. 46-56.

7. Gessert Dzh. Istoriya iskusstva s privlecheniem DNK // Logos. 2006. № 4. S. 127-147.

8. Nikulina E.E. Stilevye osobennosti ikonopisi Karelii serediny XVII -vtoroi poloviny XVIII vekov. Po materialam kollektsii muzeya izobrazitel'nykh iskusstv Respubliki Kareliya: Avtoref. diss. ... na soisk. kand. iskusstvovedeniya // http://vak.ed.gov.ru/dis-details?xPARAM=180449

9. Smirnov I.P. Istoriya mysli - istoriya filosofii: problema differentsiatsii // Filosofskie nauki. 2013. № 4. S. 31-34.

10. Bychkov V.V. Khudozhestvennost' kak sushchnostnyi printsip iskusstva // Voprosy filosofii. 2015. № 3. S. 3-14.

11. Zimmel' G. Izbrannoe: v 2-kh t. T. 1. Filosofiya kul'tury. M.: Yurist, 1996. S. 51. 